The Great Barrier Reef and Adjacent Isles By Keith Gillett and Frank McNeill. Pp. xiii +194 (161 plates). (Paddington, Sydney : Coral Press, Pty., Ltd., 1959.) 70s. (Australian).

TOURISTS with an interest in Nature will find all that they can desire in this book on the Great Barrier Reef of Australia by Keith Gillett and Frank MeNeill. This is a first-class naturalist's guide book starting with a brief introductory account and taking the visitor first to the southerly CapricornBunker group of islands. Then follow an account of the animals and plants to be found on land, an introduction to corals, and chapters devoted to molluscs, echinoderms, crustaceans, and other of the more striking reef inhabitants. This prepares the traveller for a journey farther north to the Cumberland group and other islands where a similar fauna will be found. An account is also given of Lord Howe Island and the Admiralty Islands.

There are other chapters on the resources of the reef, and the technique of underwater photography, together with practical hints for reef visitors. The book is well supplied with maps, and has good indexes to subjects and scientific names. It also includes mention of travel and tourists' facilities, including the underwater observatory at Green Island off Cairns. The interesting narrative is illustrated with superb photographs, many of which are in colour. The Great Barrier Reef is famous for the variety and splendour of its living organisms, and many of these are most beautifully portrayed. In fact, with this book the visitor can identify with certainty most of those animals which by their striking colour or form at once attract the naturalist.'s attention. The authors and publishers are to be congratulated on producing an authentic and beautiful handbook and guide, suitable for professional, as well as amateur, biologists, which will undoubtedly increase the enjoyment and value of a visit to the reef. It should also be in the library of those biologists not fortunate enough to go and see for themselves.

F. S. Russell

Proceedings of the International Conference on Scientific Information, Washington, D.C.

November 16-21, 1958. Vol. 1: Pp. xxiv +1-812. Vol. 2 : Pp. xii +813-1635. (Washington, D.C. : National Academy of Sciences-National Research Council, 1959.) 20 dollars the two volumes.

TEN years after the Royal Society Scientific Information Conference, the International Conference on Scientific Information, sponsored by the National Science Foundation, the National Research Council-National Academy of Sciences and the American Documentation Institute, was held in Washington in November 1958. All the Conference papers were issued as preprints to those who attended, but these are now re-published in two handsome volumes, together with additional material consisting of a memoriam to Dr. Alberto Thompson, who died before the Conference but who did so much towards its preparation, a preface by Dr. Wallace Atwood, jun., and the stimulating and scintillating opening address given by Sir Lindor Brown, one of the secretaries of the Royal Society. Moreover, the volumes contain the collected wisdom of the deliberations of the discussion panels and, in some instances, reports of the Conference discussions ; there are also a list of those who attended and an index.
The papers cover the literature and reference needs of the scientist and their effectiveness, abstracting services, the organization of information services and storage and search systems, and the responsibilities of Governments and others in these fields. Some are verbose, some inconclusive, but there is much worth reading and pondering over. No rigid recommendations were made by the Conference, but, as Dr. Atwood remarked at the time, "tis better to travel hopefully than to arrive". Scientific information bristles with complex problems, and while we travel hopefully towards their solution, the arrival of this important contribution to the literature is welcome.

C. A. RoNan

\section{Lehrbuch der Physikalischen Chemie}

Von Prof. John Eggert. Achte, neubearbeitete Auflage. Gemeinsam verfasst von Prof. John Eggert, Prof. Lothar Hock und Prof. Georg-Maria Schwab. Pp. xii +891. (Stuttgart: S. Hirzel Verlag, 1959.) 72 D.M.

7 HIS well-known book has been extensively revised and enlarged as compared with the English translation, and has to some extent lost its character as a readable elementary work and become a concise treatise on all branches of physical chemistry. Very recent work has been incorporated and there are abundant cross-references printed in the margins. References to literature are not given, apart from a list of books, mostly German and American, at the end, but the names of authors and the dates given will enable the publications to be traced in the abstract literature. The text is clearly and concisely written, and the mathematics is confined to elementary calculus. The sections on atomic physics and nuclear reactions are extensive, but the wave-mechanical theory of valency is only briefly treated. Experimental methods are dealt with concisely and there are many useful tables and graphs. As examples of modern topies the sections on low temperatures, semiconductors and reactions in solids may be mentioned. The chapters on photochemistry and colloids are good. The book covers all the branches of physical chemistry, and besides being a readable text-book it will be useful for reference purposes. The authors have evidently taken much trouble in the presenta. tion of the material and the book will without doubt continue to be one of the best in its field.

J. R. Partington

\section{Revision Notes on Biology for " $O$ " Level of the G.C.E.}

By G.T. Bolton. Pp. 17. (Oxford : Basil Blackwell, 1960.) $1 s .9 d$. net.

70 supplement existing text books for the 1 Ordinary Level examination in biology for the General Certificate of Education, G. T. Bolton, a biology master at Fiton College, has prepared a set of notes which will be useful to all candidates in the twelve months before the examination. The notes include a number of lists and tables which the candidate can expand for himself into a full essay on the appropriate subject. The essential facts are briefly and boldly stated, but the notes can in no way be regarded as a substitute for a text-book. Some examination topics do not lend themselves to treatment in this way, and among the omissions are experiments which illustrate physiological processes in trees and plants throughout the year. 